\title{
HUBUNGAN INTER DIALITIC WEIGHT GAINS (IDWG) DENGAN TERJADINYA KOMPLIKASI DURANTE HEMODIALISIS PADA PASIEN GINJAL KRONIK
}

\author{
Harry Permana Wibowo ${ }^{1}$, Wasal Desrial Siregar ${ }^{2}$ \\ ${ }^{1.2}$ Institut Kesehatan Sumatera Utara \\ Email: harrypermanawibowo@gmail.com
}

\begin{abstract}
Weight gain is based on dry weight. When the body has to bear excess fluid between two dialysis times, this is what is called interdialitic body weight / Inter Dialitic Weight Gain (IDWG). IRR in 2015 noted the most frequent complication in hemodialysis durante was hypertension (38\%), followed by hypotension (15\%), where the etiology of the two complications above is very closely related to the number of ultrafiltration. The purpose of this study was to determine the relationship between inter dialitic weight gains (IDWG) with the occurrence of complications of durante hemodialysis. By using a research design analytic method that uses a cross sectional approach. The sampling technique uses total sampling, in which 60 respondents measured body weight and blood pressure and observed whether experiencing complications durante hemodialysis. Furthermore, the results of observations are written in the observation sheet and tested by statistical data with the Chi-Square Test. The results showed the majority of respondents had a moderate IDWG of 33 people (55\%), of which 27 people (45\%) had complications consisting of 7 people (11.7\%) hypotension and 20 people (33.3\%) hypertension. Statistical test results with the chi-square test showed that the value of $p=0,000$, which means that there is a significant relationship between IDWG and the occurrence of complications of hemodialysis durante. Future researchers are expected to be able to further develop research on other complications that may occur related to IDWG.
\end{abstract}

Keywords: body weight, hemodialysis, IDWG, complications

\section{PENDAHULUAN}

Hemodialisis pada hakikatnya
merupakan salah satu cara untuk mengganti sebagian fungsi ginjal dengan cara membuang bahan - bahan antara lain air dan toksin uremik keluar tubuh. Berbeda dengan cara kerja ginjal alamiah yang bekerja sepanjang waktu, hemodialisis dilakukan tidak sepanjang waktu namun dalam waktu tertentu saja. Dengan demikian proses pembuangan ini terjadi dalam periode waktu yang lebih singkat dan secara lebih mendadak. Hemodialisis biasanya dilakukan 2 kali seminggu selama 4,5 jam sampai dengan 5,5 jam setiap sesinya atau 3 kali seminggu selama 4 sampai dengan 4,5 jam setiap sesinya. Frekuensi dan lamanya hemodialisis ini bertujuan untuk mencapai keadaan yang disebut "dialisis cukup" (adekuat), yakni kondisi cairan tubuh optimal yang dicapai oleh proses purifikasi darah. Dalam keadaan ini pasien akan merasa segar dan nafsu makannya normal.

Upaya mencapai Visi dan Misi 
Indonesia sehat 2025 sampai saat ini masih mengalami berbagai kendala hal ini dikarenakan masih tingginya masalah-masalah penyakit degeneratif. Beberapa dari penyakit tersebut adalah Penyakit Gagal Ginjal Kronis (GGK) atau Cronik Kidney Disease (CKD) (Kementerian Kesehatan RI, 2017). Menurut data dari Kemenkes RI, (2013) prevalensi gagal ginjal kronik di Indonesia sekitar $0,2 \%$. Prevalensi kelompok umur $\geq 75$ tahun dengan $0,6 \%$ lebih tinggi daripada kelompok umur yang lain. Prevalensi gagal ginjal kronik di Provinsi Riau yaitu $0,1 \%$.

Berdasarkan $9^{\text {th }}$ Annual Report of Indonesian Renal Registry (IRR) tahun 2016 disebutkan bahwa dari 460 unit hemodialisis yang tersebar di Indonesia, sudah terdapat 52.835 orang pasien aktif yang terus menjalani hemodialisis. Hal ini tidak lepas dari penambahan jumlah pasien baru sekitar $17 \%$ dari tahun 2015 yaitu sebanyak 21.050 orang menjadi 25.446 orang di tahun 2016. Provinsi Sumatera Utara sendiri pada tahun 2016 tercatat sebanyak 67.258 tindakan per bulan, dimana $51 \%$ nya menjalani terapi hemodialisis berdurasi 3-4 jam saja. Hal ini masih di bawah standar durasi tindakan hemodialisis yang sebaiknya 5 jam karena pada umumnya pasien hanya mendapat tindakan hemodialisis 2 kali seminggu (PPERNEFRI, 2016).
Berat badan merupakan hasil peningkatan atau penurunan semua jaringan yang ada pada tubuh. Berat badan menjadi indikator terpenting pada pasien yang menjalani dialisis. Peningkatan berat badan secara signifikan dalam rentang beberapa hari mengindikasikan adanya kelebihan cairan dalam tubuh pasien. Inilah salah satu faktor yang menyebabkan begitu pentingnya pengukuran berat badan secara rutin oleh pasien yang menjalani dialisis. Perawat memantau peningkatan berat badan tersebut untuk menentukan berat badan terendah yang dapat ditoleransi oleh pasien, yang disebut dengan berat badan kering. Peningkatan berat badan didasarkan pada berat badan kering. Saat tubuh harus menanggung kelebihan cairan diantara dua waktu dialisis, ini lah yang disebut dengan berat badan interdialitik / Interdialitic Weigh Gain (IDWG). Untuk menghindari peningkatan berat badan secara simultan, perawat mengedukasikan kepada pasien dan keluarga melakukan pembatasan intake cairan (Istanti, 2014).

Menurut Bayhakki dan Hasneli, (2018) IDWG yang dapat ditoleransi oleh tubuh adalah tidak lebih dari 3\% dari berat kering. IDWG dapat diklasifikasikan berdasarkan persentase kenaikan berat badan pasien, dimana IDWG dikatakan ringan bila 
penambahan berat badan $<4 \%$, IDWG sedang bila penambahan berat badan 4$6 \%$ dan IDWG berat jika penambahan berat badan $>6 \%$ (Istanti, 2014). Berman, Snyder, \& Frandsen, (2016) mengklasifikasikan penambahan berat badan menjadi 3 kelompok, yaitu ringan $2 \%$, sedang $5 \%$ dan berat $8 \%$.

IRR pada tahun 2015 mencatat komplikasi yang paling sering terjadi pada durante hemodialisis adalah hipertensi (38\%), yang disusul dengan hipotensi (15\%), dimana etiologi dari kedua komplikasi di atas sangat berkaitan erat dengan jumlah ultrafiltasi (PERNEFRI, 2015).

Hipotensi Intradialitik merupakan komplikasi akut yang paling sering ditemui pada pasien Penyakit Ginjal Kronik (PGK) yang menjalani hemodialisis rutin dengan angka kejadian mencapai 25 - $55 \%$ tiap sesi Hipotensi Intradialitik sering ditemui pada wanita dan pasien berusia lanjut, dengan gejala berupa mual, muntah, menguap, pusing, gelisah, nyeri dada dan pandangan gelap (Naysilla \& Partiningrum, 2012).

Hipertensi Intradialitik merupakan komplikasi yang cukup dikenal dngan insidensi $5 \%-15 \%$ pada pasien PGK yang menjalani hemodialisis rutin, namun belum banyak mendapat perhatian. Hipertensi Intradialitik berkaitan dengan kelebihan cairan signifikan interdialitik dan berkaitan dengan tingginya ultrafiltrasi selama sesi dialisis. Beberapa laporan menunjukkan bahwa Hipertensi Intradialitik berkaitan dengan hiperaktivitas sistem saraf simpatis, gangguan fungsi endotel dan peningkatan curah jantung akibat pengeluaran cairan (ultrafiltrasi). (Astuti \& Endang, 2018).

Menurut Irwanti, Indrayana, dan Wahyuni (2014) dalam kepatuhan pasien gagal ginjal kronik dalam mempertahankan berat badan diantara dua waktu dialisis menyebutkan bahwa IDWG yang melebihi $5 \%$ dari berat badan kering dapat menimbulkan sesak nafas, edema paru dan edema perifer. Sementara itu, Armiyati (2012) menyebutkan bahwa dari 50 orang pasien yang diteliti menunjukkan70\% pasien mengalami hipertensi intradialisis, 26\% mengalami hipotensi intradialisis. Frekuensi hipertensi intradialisis adalah $55 \%$ dari keseluruhan prosedur hemodialisis yang diamati dan paling banyak dialami pasien pada jam ke empat. Frekuensi hipotensi intadialisis adalah $12 \%$ dari keseluruhan prosedur hemodialisis yang diamati dan paling banyak dialami pada jam pertama.

Banyak faktor yang berkontribusi terhadap terjadinya IDWG, diantaranya adalah faktor dari pasien dan keluarga. Beberapa faktor psikososial sangat 
berhubungan dengan peningkatan IDWG seperti faktor demografi, masukan cairan, rasa haus, social support, self efficacy dan stress (Ipema et al., 2016).

Rumah Sakit Universitas Sumatera Utara adalah salah satu rumah sakit pendidikan di bawah Kementerian Riset, Teknologi dan Pendidikan Tinggi yang berada di Provinsi Sumatera Utara. Rumah sakit ini mulai operasional penuh pada tanggal 28 Maret 2016. Salah satu produk layanan Rumah Sakit Universitas Sumatera Utara adalah Hemodialisis. Saat ini RS USU telah memiliki 18 mesin hemodialisis yang siap beroperasi. Berdasarkan survei awal yang peneliti lakukan, jumlah pasien pada bulan April 2018 yaitu sebanyak 60 orang dengan jumlah tindakan hemodialisis sebanyak 480 tindakan dalam satu bulan. Hasil dari 10 pasien yang peneliti observasi, sekitar $70 \%$ pasien mengalami IDWG kategori sedang sampai berat dengan 57\% diantaranya mengalami komplikasi intradialitik berupa hipotensi dan kram otot.

Berdasarkan latar belakang di atas, maka peneliti tertarik untuk meneliti bagaimanahubungan Inter Dialitic Weight Gains (IDWG) dengan terjadinya komplikasi durante hemodialisis pada pasien Penyakit Ginjal Kronis yang menjalani hemodialisis di Unit Hemodialisis RS Universitas Sumatera Utara tahun 2018.

\section{METODE}

Metode penelitian yang digunakan dalam penelitian ini adalah analitik dengan menggunakan pendekatan secara crosssectional. Penelitian ini dilakukan di Rumah Sakit Universitas Sumatera Utara pada tanggal 06 - 11 Agustus 2018.

Populasi penelitian adalah keseluruhan objek penelitian atau objek yang diteliti (Notoatmodjo, 2012). Populasi adalah seluruh pasien hemodialisis yang menjalankan terapi hemodialisisnya di RS Universitas Sumatera Utara yang berjumlah 60 orang. Teknik pengambilan sampel dalam penelitian ini adalah non propability sampling dengan cara total sampling. Jumlah sampel yang digunakan dalam penelitian ini yang memenuhi kriteria inklusi adalah sebanyak 60 orang.

Penelitian ini menggunakan instrument yang berisi pertanyaan yang telah dikembangkan oleh peneliti berdasarkan literatur yang mengacu pada kerangka konsep berisi karakteristik demografi (usia, jenis kelamin, pendidikan, riwayat penyebab gagal ginjal, berat badan kering, pekerjaan/aktivitas), lamanya klien telah menjalani terapi hemodialisis. 
Analisa data meliputi: analisa univariat dan bivariat. Analisa univariat menjelaskan tentang karakteristik responden, dan analisa bivariat untuk melihat hubungan antara variabel independen (IDWG) dengan variabel dependen (komplikasi durante HD) dengan menggunakan Uji Chi-Square.

\section{HASIL DAN PEMBAHASAN}

\section{Analisa Univariat}

Analisa Univariat dilakukan untuk melihat distribusi frekuensi karakteristik IDWG dengan terjadinya komplikasi durante hemodialysis.

Tabel 1. Distribusi

Frekuensi

Responden Berdasarkan Usia di Unit Hemodialisis

\begin{tabular}{ccc}
\hline $\begin{array}{c}\text { Usia } \\
\text { (Tahun) }\end{array}$ & $\begin{array}{c}\text { Frekuensi } \\
(\boldsymbol{f})\end{array}$ & $\begin{array}{c}\text { Persentase } \\
(\boldsymbol{\%})\end{array}$ \\
\hline$\leq 60$ & 43 & 71,7 \\
$>60$ & 17 & 28,3 \\
\hline Jumlah & 60 & 100 \\
\hline
\end{tabular}

Berdasarkan Tabel 1 di atas diketahui bahwa mayoritas responden berusia $\leq$ 60 tahun yaitu sebanyak 43 orang (71.7 $\%$ ) dan yang berusia > 60 tahun yaitu sebanyak 17 orang $(28.3 \%)$.

\section{Tabel 2. Distribusi Frekuensi Responden Berdasarkan Jenis Kelamin di Unit Hemodialisis}

\begin{tabular}{ccc}
\hline $\begin{array}{c}\text { Jenis } \\
\text { Kelamin }\end{array}$ & $\begin{array}{c}\text { Frekuensi } \\
(\boldsymbol{f})\end{array}$ & $\begin{array}{c}\text { Persentase } \\
(\boldsymbol{\%})\end{array}$ \\
\hline Laki-Laki & 36 & 60 \\
Perempuan & 24 & 40 \\
\hline Jumlah & 60 & 100 \\
\hline
\end{tabular}

Berdasarkan Tabel 2 di atas diketahui bahwa responden yang berjenis kelamin laki - laki yaitu berjumlah 36 orang (60 $\%$ ) dan responden perempuan berjumlah 24 orang $(40 \%)$.

Tabel 3. Distribusi Responden Berdasarkan Pendidikan di Hemodialisis

\begin{tabular}{lcc}
\hline Pendidikan & $\begin{array}{c}\text { Frekuensi } \\
(\boldsymbol{f})\end{array}$ & $\begin{array}{c}\text { Persentase } \\
(\boldsymbol{\%})\end{array}$ \\
\hline SD & 1 & 1,7 \\
SMP & 1 & 1,7 \\
SMA & 41 & 68,3 \\
Perguruan & 17 & 28,3 \\
Tinggi & & \\
\hline \multicolumn{1}{c}{ Jumlah } & 60 & 100 \\
\hline
\end{tabular}

Berdasarkan Tabel 3 di atas diketahui bahwa mayoritas responden berpendidikan SMA berjumlah 41 orang (68,3\%), berpendidikan Perguruan Tinggi sebanyak 17 orang $(28,3 \%)$, berpendidikan SMP sebanyak 1 orang $(1,7 \%)$ dan berpendidikan SD sebanyak 1 orang $(1,7 \%)$.

\section{Tabel 4. Distribusi Frekuensi \\ Responden Berdasarkan \\ Riwayat Penyebab \\ Gagal Ginjal di Unit Hemodialisis}

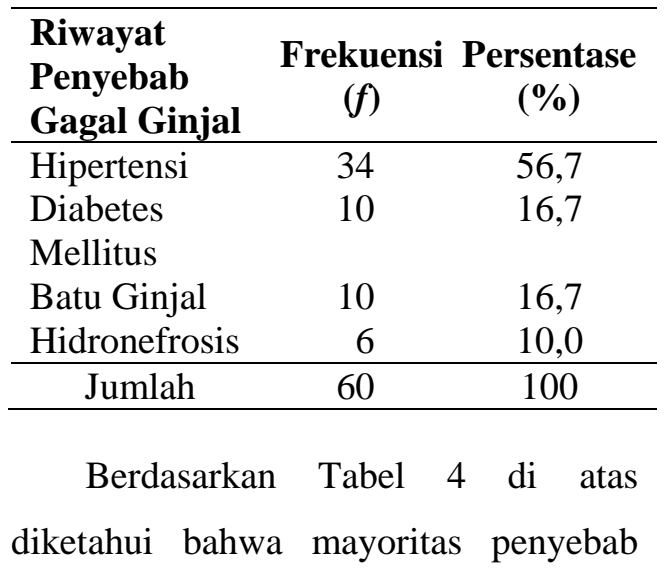


gagal ginjal adalah Hipertensi dengan jumlah responden sebanyak 34 orang (56,7\%), Diabetes Melitus sebanyak 10 orang (16,7\%), Batu Ginjal sebanyak 10 orang $(16,7 \%)$, dan Hidronefrosis sebanyak 6 orang (10\%).

Tabel 5.

$\begin{array}{lrr}\text { Distribusi } & \text { Frekuensi } \\ \text { Responden } & \begin{array}{r}\text { Berdasarkan } \\ \text { Berat }\end{array} \\ \text { Kering } & \text { di } & \text { Undan } \\ \text { Hemodialisis } & & \end{array}$

\begin{tabular}{lcc}
\hline $\begin{array}{c}\text { Berat } \\
\text { Badan } \\
\text { Kering } \\
(\mathbf{K g})\end{array}$ & $\begin{array}{c}\text { Frekuensi } \\
(\boldsymbol{f})\end{array}$ & $\begin{array}{c}\text { Persentase } \\
(\boldsymbol{\%})\end{array}$ \\
\hline$<60$ & 11 & 18,3 \\
$60-90$ & 48 & 80,0 \\
$>90$ & 1 & 1,7 \\
\hline Jumlah & 60 & 100 \\
\hline
\end{tabular}

Berdasarkan Tabel 5 di atas diketahui bahwa mayoritas berat badan kering responden berada pada berat 60 $90 \mathrm{Kg}$ yaitu berjumlah 48 Orang (80\%), berat badan kering $<60 \mathrm{Kg}$ yaitu berjumlah 11 orang $(18,3 \%)$, berat badan kering $>90 \mathrm{Kg}$ berjumlah 1 orang $(1,7 \%)$.

\begin{tabular}{|c|c|c|}
\hline Tabel & $\begin{array}{l}\text { Distribusi } \\
\text { Responden } \\
\text { Lama }\end{array}$ & $\begin{array}{r}\text { Frekuensi } \\
\text { Berdasarkan } \\
\text { Menjalani }\end{array}$ \\
\hline & $\begin{array}{l}\text { Hemodialisis } \\
\text { Hemodialisis }\end{array}$ & Unit \\
\hline
\end{tabular}

\begin{tabular}{lcc}
\hline $\begin{array}{l}\text { Lama } \\
\text { Menjalani }\end{array}$ & $\begin{array}{c}\text { Frekuensi } \\
(\boldsymbol{f})\end{array}$ & $\begin{array}{c}\text { Persentase } \\
(\boldsymbol{\%})\end{array}$ \\
HD & & 0 \\
(Tahun) & 0 & 90 \\
$<1$ & 54 & 10 \\
$1-3$ & 6 & 100 \\
\hline \multicolumn{1}{c}{ Jumlah } & 60 & \\
\hline
\end{tabular}

Berdasarkan Tabel 6 di atas diketahui bahwa mayoritas responden sudah menjalani hemodialisis selama 1 3 tahun yaitu berjumlah 54 orang (90\%) dan yang menjalani > 3 tahun yaitu sebanyak 6 orang $(10 \%)$.

$\begin{array}{llr}\text { Tabel 7. } & \begin{array}{l}\text { Distribusi } \\ \text { Responden }\end{array} & \begin{array}{r}\text { Frekuensi } \\ \text { Berdasarkan }\end{array} \\ & \text { Inter } & \text { Dialitic } \\ \text { Weight Gains } & \text { (IDWG) di } \\ & \text { Unit Hemodialisis }\end{array}$

\begin{tabular}{lcc}
\hline \multicolumn{1}{c}{ IDWG } & $\begin{array}{c}\text { Frekuensi } \\
(\boldsymbol{f})\end{array}$ & $\begin{array}{c}\text { Persentase } \\
(\boldsymbol{\%})\end{array}$ \\
\hline Ringan & 6 & 10 \\
Sedang & 33 & 55 \\
Berat & 21 & 35 \\
\hline Jumlah & 60 & 100 \\
\hline
\end{tabular}

Berdasarkan Tabel 7 di atas diketahui bahwa mayoritas responden memiliki IDWG sedang yaitu berjumlah 33 orang (55\%), sedangkain lainnya memiliki IDWG berat yaitu berjumlah 21 orang $(35 \%)$ dan IDWG ringan yaitu berjumlah 6 orang (10\%).

\section{Tabel 8. Distribusi Frekuensi Responden Berdasarkan Komplikasi Durante Hemodialisis di Unit Hemodialisis}

\begin{tabular}{lcc}
\hline Komplikasi & $\begin{array}{c}\text { Frekuensi } \\
(\boldsymbol{f})\end{array}$ & $\begin{array}{c}\text { Persentase } \\
(\mathbf{\%})\end{array}$ \\
\hline Tidak & 33 & 55,0 \\
Terjadi & & \\
Hipotensi & 7 & 11,7 \\
Hipertensi & 20 & 33,3 \\
\hline Jumlah & 60 & 100 \\
\hline
\end{tabular}

Berdasarkan Tabel 8 di atas diketahui bahwa 33 orang responden (55\%) tidak mengalami komplikasi durante HD dan 27 orang (45\%) mengalami komplikasi 
yang terdiri dari Hipotensi 7 orang $(11,7 \%)$ dan Hipertensi 20 orang $(33,3 \%)$.

\section{Analisa Bivariat}

Analisa Bivariat bertujuan untuk mengetahui ada tidaknya hubungan yang bermakna antara variabel dependen dan variabel independen yaitu hubungan IDWG dengan terjadinya komplikasi durante HD di Unit Hemodialisis RS Universitas Sumatera Utara tahun 2018 dengan menggunakan uji statistik.

Tabel 9. Tabulasi Silang IDWG dengan Komplikasi Durante Hemodialisis di Unit Hemodialisis

\begin{tabular}{|c|c|c|c|c|c|c|c|}
\hline \multirow{3}{*}{ IDWG } & \multicolumn{4}{|c|}{ Komplikasi Durante HD } & \multirow{3}{*}{ Total } & \multirow{3}{*}{$\%$} & \multirow{3}{*}{ pValue } \\
\hline & \multicolumn{2}{|c|}{ Tidak Terjadi } & \multicolumn{2}{|c|}{ Terjadi } & & & \\
\hline & $f$ & $\%$ & $f$ & $\%$ & & & \\
\hline Ringan & 6 & 10 & 0 & 0 & 6 & 10 & \\
\hline Sedang & 26 & 43,5 & 7 & 11,5 & 33 & 55 & 0.000 \\
\hline Berat & 1 & 1,6 & 20 & 33,4 & 21 & 35 & \\
\hline Jumlah & 33 & 55 & 27 & 45 & 60 & 100 & \\
\hline
\end{tabular}

Berdasarkan Tabel 9 di atas dapat dilihat responden dengan IDWG Ringan yang tidak mengalami komplikasi berjumlah 6 orang (10\%). Responden dengan IDWG Sedang yang tidak mengalami komplikasi berjumlah 26 orang $(43,4 \%)$ dan yang mengalami komplikasi berjumlah 7 orang $(11,7 \%)$. Responden dengan IDWG Berat yang tidak mengalami komplikasi berjumlah 1 orang $(1,6 \%)$ dan yang mengalami komplikasi 20 orang $(33,3 \%)$.

Hasil uji statistik dengan uji chi square menunjukkan bahwa nilai $\mathrm{p}=$ 0.000 atau $\mathrm{p}=<0.05$, yang berarti bahwa ada hubungan yang signifikan antara IDWG dan terjadinya komplikasi durante hemodialisis.

\section{Pembahasan}

Hubungan Inter Dialitic Weight Gains (IDWG) dengan Komplikasi Durante Hemodialisis

Hasil penelitian menunjukkan, responden dengan IDWG Ringan yang berjumlah 6 orang (10\%) tidak mengalami komplikasi durante HD. Responden dengan IDWG Sedang yang tidak mengalami komplikasi berjumlah 26 orang $(43,4 \%)$ dan yang mengalami komplikasi berjumlah 7 orang $(11,7 \%)$. Responden dengan IDWG Berat yang tidak mengalami komplikasi berjumlah 1 orang $(1,6 \%)$ dan yang mengalami komplikasi 20 orang $(33,3 \%)$. Dimana dari komplikasi yang terjadi diketahui bahwa Hipotensi 7 orang $(11,7 \%)$ mengalami Hipotensi dan 20 orang $(33,3 \%)$ mengalami Hipertensi. 
Muharrom, Suryono, dan Komariah, (2018) menyebutkan penambahan berat badan yang berlebihan diantara waktu dialisis dapat menimbulkan komplikasi dan masalah bagi pasien diantaranya yaitu: hipertensi yang semakin berat, gangguan fungsi fisik, sesak nafas, edema pulmonal yang dapat meningkatkan kemungkinan terjadi kegawatdaruratan hemodialisis, meningkatnya resiko dilatasi, hipertropi ventrikuler dan gagal jantung.

Hipotensi intradialitik merupakan respon kardiovaskuler yang tidak adekuat terhadap reduksi volume darah. Kemampuan memelihara volume plasma selama proses ultrafiltrasi membutuhkan mobilisasi cairan dari ruang interstitial ke ruang intravaskuler. Jumlah cairan untuk pengisian kembali pembuluh darah dipengaruhi oleh berat badan kering pasien. Jika berat badan kering pasien lebih rendah dari berat badan kering sebenarnya dapat menyebabkan ketidakstabilan hemodinamik yang diikuti hipotensi (Isroin, 2014).

Hasil penelitian Fazriansyah., Farhandika dan Gathut (2018) menunjukkan kepatuhan pasien dalam mengontrol intake (asupan) cairan hampir seluruhnya responden dalam kategori tidak patuh dan hasil penambahan berat badan diantara dua waktu hemodialisis (inter-dialytic weight gain = IDWG) sebagian besar responden dalam kategori penambahan sedang. Hal ini mendapatkan hubungan antara kepatuhan mengontrol intake (asupan) cairan dengan penambahan nilai inter-dialytic weight gain (IDWG) pada pasien yang menjalani terapi hemodialisis di RSUD Kotabaru.

Berdasarkan pengamatan lapangan, peneliti melihat pasien-pasien yang datang dengan IDWG Ringan dan Sedang, dapat menjalani HD dengan aman dan nyaman tanpa mengalami komplikasi. Namun sebaliknya, pada pasien yang memiliki IDWG Sedang sampai Berat, mayoritas mengalami komplikasi, baik dengan menunjukkan manifestasi klinis maupun tidak. Beberapa hal yang dijadikan alasan oleh beberapa pasien - pasien tersebut adalah mengeluhkan cuaca yang kebetulan sedang panas sehingga meningkatkan rasa haus, bahkan ada juga yang memang sengaja meminum cairan berlebih karena sudah biasa dengan penambahan berat badan yang banyak dan beranggapan cairan yang berlebih tersebut dapat dibuang habis saat menjalani HD. Sebagian pasien memang masih merasa biasa - biasa saja karena memang terkadang pada situasi- situasi tertentu hal ini hanya menimbulkan gejala-gejala sebatas kaki yang bengkak dan sesak yg belum begitu mengganggu. 
Namun, akan sangat disayangkan apabila dalam pemeriksaan pemeriksaan rutin selanjutnya, baru diketahui telah terjadi hipertrovi ventrikel kiri, efusi pleura atau acites yang sudah tentu penanganannya akan menjadi lebih sulit.

\section{KESIMPULAN DAN SARAN}

\section{Kesimpulan}

1. IDWG yang melebihi IDWG Sedang memiliki hubungan yang signifikan terhadap terjadinya komplikasi Hipertensi dan Hipotensi durante Hemodialisis.

2. Kelompok IDWG Ringan dan IDWG Sedang tidak memiliki perbedaan dalam proporsi terjadinya komplikasi durante Hemodialisis.

3. Kelompok IDWG Ringan dan IDWG Berat memiliki perbedaan dalam proporsi terjadinya komplikasi durante Hemodialisis dan memiliki korelasi yang kuat.

4. Kelompok IDWG Sedang dan IDWG Berat memiliki perbedaan dalam proporsi terjadinya komplikasi durante Hemodialisis dan memiliki korelasi yang cukup.

\section{Saran}

1. Perlunya dilakukan edukasi secara terus menerus dan menggunakan cara persuasif agar memberikan kesadaran kepada pasien untuk lebih memperhatikan kenaikan berat badan antar sesi dialisis.

2. Peneliti selanjutnya diharapkan agar dapat lebih mengembangkan penelitian mengenai komplikasi lainnya yang mungkin terjadi terkait IDWG, serta membuat intrumen untuk menilai komplikasi terjadinya kram otot.

\section{DAFTAR PUSTAKA}

Armiyati, Y. (2012). Hipotensi dan hipertensi intradialisis pada pasien Chronic Kidney Disease ( CKD ) saat menjalani hemodialisis. Seminar Hasil-Hasil PenelitianLPPM UNIMUS.

Astuti, S. D., \& Endang, E. (2018). Kajian Penggunaan Antihipertensi dan Potensi Interaksi Obat Pada Pengobatan Pasien Hipertensi Dengan Komplikasi. Jurnal Farmasi Indonesia. https://doi.org/10.31001/jfi.v15i2.4 83

Bayhakki, B., \& Hasneli, Y. (2018). Hubungan Lama Menjalani Hemodialisis dengan Inter-Dialytic Weight Gain (IDWG) pada Pasien Hemodialisis. Jurnal Keperawatan Padjadjaran.

https://doi.org/10.24198/jkp.v5i3.6 46

Berman, A., Snyder, S. J., \& Frandsen, G. (2016). Kozier and Erb's Fundamentals of Nursing Concepts, Process, and Practice Tenth Edition. In Kozier and Erb's Fundamentals of Nursing.

Fazriansyah., Farhandika, P., Gathut, P. (2018). Hubungan Antara Kepatuhan Mengontrol Intake (Asupan) Cairan Dengan Penambahan Nilai Inter-Dialytic Weight Gain (IDWG) Pada Pasien Yang Menjalani Terapi Hemodialisis di RSUD Kotabaru. Dinamika Kesehatan, 9(2). Retrieved from 
https://ojs.dinamikakesehatan.unis m.ac.id/index.php/dksm/article/vie w/348

Ipema, K. J. R., Kuipers, J., Westerhuis, R., Gaillard, C. A. J. M., Van Der Schans, C. P., Krijnen, W. P., \& Franssen, C. F. M. (2016). Causes and Consequences of Interdialytic weight gain. Kidney and Blood Pressure Research. https://doi.org/10.1159/000450560 Irwanti, W., Indrayana, S., \& wahyuni. (2014). Korelasi Penambahan Berat Badan Diantara Dua Waktu Dialisis dengan Kualitas Hidup Pasien Menjalani Hemodialisa. Journal Ners And Midwifery Indonesia.

Isroin, L. (2014). Manajemen Cairan pada Pasien Hemodialisis Untuk Meningkatkan Kualitas Hidup di RSUD Dr. Harjono Ponorogo. IJNP (Indonesian Journal of Nursing Practices).

Istanti, yuni permatasari. (2014). Hubungan Antara Masukan Cairan Dengan Interdialytic Weight Gain (IDWG) Pada Pasien Chronic Kidney Diseases Di Unit Hemodialisis RS PKU Muhammadiyah Yogyakarta. Profesi.

Kemenkes RI. (2013). RISKESDAS 2013.https://doi.org/10.1517/13543 784.7.5.803

Kementerian Kesehatan RI. (2017). Masalah hipertensi di Indonesia. Kementerian Kesehatan RI.

Muharrom, N. A., Suryono, \& Komariah, C. (2018). Hubungan Quick of Blood dengan kejadian hipertensi intradialisis pada pasien penyakit ginjal kronik stadium $\mathrm{V}$ di RSD dr. Soebandi Jember. Journal of Agromedicine and Medical Sciences.

Naysilla, A. M., \& Partiningrum, D. L. (2012). Faktor risiko hipertensi intradialitik pasien penyakit ginjal kronik. Jurnal Kedokteran Diponegoro.
Notoatmodjo, S. (2012). Metodologi Penelitian Kesehatan.

PERNEFRI. (2015). 8th Report Of Indonesian Renal Registry. Program Indonesia Renal Registry. https://doi.org/10.2215/CJN.02370 316

PPERNEFRI. (2016). Program Indonesian Renal Registry. Report Of Indonesian Renal Registry 2016. Perkumpulan Nefrologi Indonesia. 